\title{
Evaluation of dietary Intake and Food Patterns of Adolescent Girls in Sistan and Baluchistan Province, Iran
}

\section{Farzaneh Montazerifar*1, Mansour Karajibani' ${ }^{1}$, and Ali Reza Dashipour ${ }^{2}$}

${ }^{1}$ Departments of Nutrition, School of Medicine, Research Center for Health Promotion and Social Development, Zahedan University of Medical Sciences, Zahedan, Iran; ${ }^{2}$ Departments of Nutrition, School of Medicine, Zahedan University of Medical Sciences, Zahedan, Iran

*Correspondence: Farzaneh Montazerifar, Department of Nutrition, School of Medicine, Zahedan University of Medical Sciences, Zahedan, Iran

Submission date: January 26, 2012, Acceptance date: April 03, 2012; Publication date: April 31, 2012

\section{Abstract:}

Background: The evidence suggests a relationship between lifestyle and diet-related risk factors.

Objective: This study assessed the dietary intake and habits of high school girls in Sistan and Bluchistan province, in southeastern Iran.

Methods: In a cross-sectional, descriptive study, 753 high school girls aged 14-18 years old were enrolled by a clustered random sampling method. Dietary intake and food habits were evaluated by a two-day, 24-hour dietary recall, and a food frequency questionnaire (FFQ).

Results: The analysis of dietary intakes showed that energy, calcium, zinc, vitamin $\mathrm{C}$ and folate intake, compared to the Dietary Reference Intake (DRI), were found to be lower. The, infrequent intake of milk and dairy products, fruits and vegetables, and a high consumption of empty calorie foods e.g. salty snacks, sweets, soft drinks and junk foods were seen among adolescents.

Conclusions: The adolescent girls had an improper dietary intake and food habits. Thus, the implementation of nutrition education programs in schools and the designing of proper patterns towards healthier food choices could help improve eating behaviors, the health maintenance of adolescents, and also prevent diet- related diseases in adulthood.

Key words: Adolescent girls, Dietary intake, Food habits.

\section{INTRODUCTION:}

Adolescence has been shown to be an important period of changes, both physiological and 
psychological. During this time, changing lifestyle and dietary habits affect dietary requirements $[1,2,3,4]$.

The association between lifestyle, the consumption of fast foods, and diet-related risk factors has been reported in some reports $[1,3]$.

Inadequate1 diet during this time can results in decreased learning ability, delayed sexual maturity, iron deficiency, anemia, lock of concentration, impaired school performance, and slow growth [4]. Additionally, unsuitable food habits increase obesity / underweight, and the risk of incidence of diet-related chronic diseases among adolescents [4].

The relationship between the development of atherosclerosis in adulthood with exposure to risk factors during childhood and adolescence has been reported in previous studies $[5,6,7]$.

Among adolescents, both under and over-nutrition are present in particular in developing countries $[8,9]$, which is represented as obese/overweight, then wasting/underweight, and in the long term as stunting $[8,10]$.

On the other hand, some of the teenage girls are under a controlled diet to reduce their body weight, which may result in nutritional deficiencies [1, 12].

Since adolescence is a critical period for the progression of healthy nutrition behaviors, $t$ adequate energy, nutrient intake, and healthy snacks in this period can lead to optimal growth, and prevent chronic diseases such as obesity, diabetes, cardiovascular disease, and hypertension [2,3].

Because of the limited information on energy and macro and macro- nutrient intake in the teenage girls of Sistan and Bluchistan Province, South-east of Iran, and considering to social, economic, and cultural conditions in this area, it seems such information could guide us for implementation of interventional programs, helping young people to avoid unbalanced diets for delaying or preventing the development of chronic diseases.

The present study addresses the intake of energy, macro and micro nutrients, as well as food frequency of high school girls in Sistan and Bluchistan Provine.

\section{MATERIALS AND METHODS:}

Subjects: In a cross-sectional study, a sample of 752 adolescent girls 14-18 years was selected from high-school students of 8 cities of Sistan va Baluchistan province by cluster sampling. Detailed explanations of the sampling and sample size calculation have been described in the earlier study [13]. Prior to the study, the adolescents were informed about the objectives and methods.

Dietary assessment: Food patterns and dietary intake data were assessed by two questionnaires, including a food frequency questionnaire (FFQ), and a two-day, 24-hour dietary recall, respectively [14]. The nutrient value of the diet was calculated by food composition analysis software. The questionnaires were filled in a personal interview that was conducted by trained investigators and a nutritionist. Dietary intake data was collected on all food items and beverages consumed on the two previous days. In order to avoid eventual differences between working and not-working days, the mean values of calories and nutrient intakes were measured on one weekday and one weekend. Mean energy and macronutrient intakes of the adolescents and energy percent $(\mathrm{E} \%)$ of carbohydrate, protein, and fat from total calories consumed, were compared with the Dietary Reference Intakes (DRI) [16]. 
Food Frequency data: The different food /drink items in FFQ included seven categories of major foods and beverages consumed by adolescents on a daily or weekly basis. These categories included: 1) Bread and Cereal group; 2) Milk and dairy products; 3) Fruits and Vegetables; 4) Meats group and substitutes; 5) Fats and sauces; 6) Sweets ( cakes, chocolate candies ,Donuts, etc); 7) Beverages (tea, soft drink and fruit juice) [15]. In addition to the questionnaires, some open-ended questions were added for the assessment of food patterns e.g. the consumption of breakfast, lunch, and dinner; the consumption pattern of fast foods (frequency and type of food), and junk foods (salty snacks).

Statistical analysis: Data were analysis by SPSS software, version 11.5, 2002, SPSS Inc., Chicago IL). The results were represented as mean \pm SD and frequency. The evaluation of eventual significant differences was carried out by one sample t-test. The difference was considered significant at $\mathrm{P}$-value $<0.05$ levels.

\section{RESULTS:}

The mean ages of the adolescent girls were 16.4 \pm 1.3 years old (range 14-18 years). As shown in Table 1, mean energy intake in different age groups was $1992.4 \pm 753.3 \mathrm{Kcal} /$ day. Mean intake and $\mathrm{E} \%$ of protein, carbohydrate and fat intake were $(70.1 \pm 21.6 \mathrm{~g} /$ day $; 14.1 \%),(269 \pm 67.8$ $\mathrm{g} /$ day $; 54 \%)$ and $(70.7 \pm 20.1 \mathrm{~g} /$ day $; 31.9 \%)$ from total calories consumed, respectively.

Table 1. Daily energy and nutrient intakes and \% of energy intake (E \%) of macronutrients in adolescent girls compared to the Dietary Reference Intakes (DRIs) [16, 17]

\begin{tabular}{lc} 
Nutrient variables & Mean \pm SD \\
\hline Energy $(\mathrm{kcal} / \mathrm{d})$ & $* 1992.4 \pm 753.3$ \\
Protein $(\mathrm{g} / \mathrm{d})$ & $70.1 \pm 21.6$ \\
\%Kcal of Protein & $14.1 \%$ \\
Carbohydrate $(\mathrm{g} / \mathrm{d})$ & $54 \%$ \\
\% Kcal of Carbohydrate & $70.7 \pm 20.1$ \\
Total fat $(\mathrm{g} / \mathrm{d})$ & $31.9 \%$ \\
\%Kcal of Fat & $95.6 \pm 23.7$ \\
Total sugar $(\mathrm{g} / \mathrm{d})$ & $15.6 \pm 8.7$ \\
Iron $(\mathrm{mg} / \mathrm{d})$ & $* 777.3 \pm 112.4$ \\
Calcium $(\mathrm{mg} / \mathrm{d})$ & $1193.6 \pm 349.1$ \\
Phosphor $(\mathrm{mg} / \mathrm{d})$ & $* 9.3 \pm 1.3$ \\
Zinc $(\mathrm{mg} / \mathrm{d})$ & $339 \pm \mathbf{1 3 4 . 5}$ \\
Magnesium $(\mathrm{mg} / \mathrm{d})$ & $1647 \pm \mathbf{4 5 6 . 7}$ \\
Sodium $(\mathrm{mg} / \mathrm{d})$ & $2232.3 \pm 956.5$ \\
Potassium $(\mathrm{mg} / \mathrm{d})$ & $763 \pm 284.4$ \\
Vitamin A $(\mu \mathrm{g} / \mathrm{d})$ & $1.8 \pm \mathbf{0 . 2}$ \\
Vitamin B1 $(\mathrm{mg} / \mathrm{d})$ & $1.8 \pm 0.7$ \\
Vitamin $\mathrm{B} 2(\mathrm{mg} / \mathrm{d})$ & $2.8 \pm 1.1$ \\
VitaminB12 $(\mu \mathrm{g} / \mathrm{d})$ & $* \mathbf{4 6 . 6} \pm \mathbf{1 4 . 5}$ \\
Vitamin C $(\mathrm{mg} / \mathrm{d})$ & $* 150.3 \pm \mathbf{4 5 . 8}$ \\
Folate $(\mu \mathrm{g} / \mathrm{d})$ &
\end{tabular}

Values are mean $\pm \mathrm{SD} . * \mathrm{P}<0.05$ 
Table 2 demonstrates that micronutrient intake values of calcium $(777.3 \pm 112.4 \mathrm{mg} /$ day $)$, zinc $(7.3$ $\pm 1.3 \mathrm{mg}$ /day $)$, vitamin $\mathrm{C}(56.6 \pm 14.5 \mathrm{mg} /$ day $)$, and folate $(150.3 \pm 49.9)$ were lower than the recommendation of DRI.

Table 2. Consumption frequency of various food items and Junk foods in adolescent girls

Consumption frequency $\quad$ Daily
Food items

\begin{tabular}{|c|c|c|c|c|c|c|c|c|c|c|}
\hline & No & $\%$ & No & $\%$ & No & $\%$ & No & $\%$ & No & $\%$ \\
\hline Bread ,rice and macaroni & 657 & 87.3 & 86 & 11.4 & 10 & 1.3 & \multicolumn{2}{|c|}{-} & \multicolumn{2}{|l|}{-} \\
\hline Milk and dairy products & 123 & 16.3 & 158 & 21 & 157 & 20.8 & 310 & 41.2 & 5 & 0.7 \\
\hline Fruit and vegetable & 122 & 16.2 & 122 & 16.2 & 40 & 5.3 & 469 & 62 & - & \\
\hline \multicolumn{11}{|l|}{ Meat group and substitutes: } \\
\hline Fish, Poultry, red meat & 240 & 31.9 & 245 & 32.5 & 199 & 26.4 & 45 & 6 & 24 & 3.2 \\
\hline Egg & 25 & 3.3 & 655 & 87 & 55 & 7.3 & 13 & 1.7 & 5 & 0.7 \\
\hline Legumes: & 405 & $\mathbf{5 3 . 8}$ & 298 & 39.6 & 38 & 5 & 10 & 1.3 & 2 & 0.3 \\
\hline \multicolumn{11}{|c|}{ kidney beans, soybeans, cowpeas,etc } \\
\hline Nuts & 5 & 0.7 & 50 & 6.6 & 345 & 45.8 & 312 & 41.4 & 43 & 5.7 \\
\hline Sauces, butter, cream & 298 & 39.6 & 315 & 41.8 & 105 & 13.9 & 30 & 4 & 5 & 0.7 \\
\hline $\begin{array}{l}\text { Sweets : } \\
\text { (cakes, chocolate, Donuts, }\end{array}$ & $\begin{array}{r}343 \\
\text { kies) }\end{array}$ & 45.5 & 357 & 47.5 & 49 & 6.5 & 3 & 0.4 & 1 & $\mathbf{0 . 1}$ \\
\hline \multicolumn{11}{|l|}{ Beverages: } \\
\hline Tea & 663 & 88 & 65 & 8.6 & 10 & 1.3 & 11 & 1.5 & 4 & 0.5 \\
\hline Soft drink & 568 & 75.4 & 162 & 21.5 & 8 & 1.1 & 11 & 1.5 & 4 & 0.5 \\
\hline Fruit juice & 20 & 2.7 & 495 & 65.7 & 205 & 27.2 & 31 & 4.1 & 2 & 0.3 \\
\hline Junk foods & 638 & 84.7 & 72 & 9.6 & 35 & 4.6 & 5 & 0.7 & 3 & 0.4 \\
\hline
\end{tabular}

In Figure 1, the percentage of adolescent girls whose usual dietary intake was less than adequate, the intake of the DRI for selected vitamins and minerals was shown. Compared to the recommendations of DRI, the most deficiencies were related to iron $(71.7 \%)$, calcium (75\%), zinc (65.6\%), vitamin C (61.90\%) and folate (97.2\%) intakes, among adolescent girls.

Fig 1.Percentage of adolescent girls ages 14-18 years whose usual dietary intake is less than adequate intake of the DRI for selected vitamins and minerals [16, 17]. 


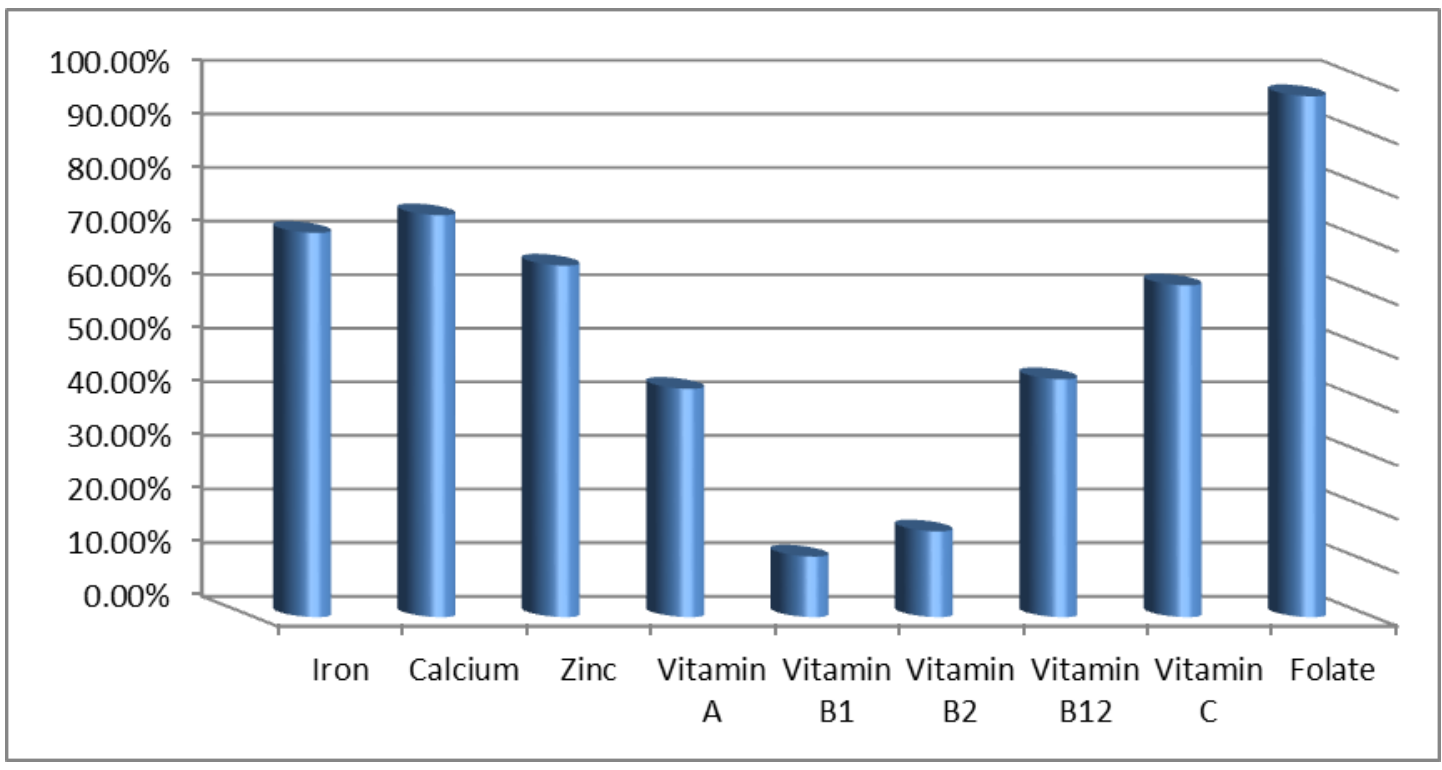

According to Table 3, the daily consumption of bread and cereals, legumes, sweets, tea and soft drinks, and junk foods were found more than other food/drink items, while the intake of meats, eggs, milk and dairy products, fruit and vegetable were low.

Table 3. Fast food consumption Frequency of the adolescent girls

\begin{tabular}{lcc} 
Food patterns & Frequency & Percentage \\
\hline Eating fast foods & 354 & \\
Yes & 400 & 53 \\
No & & \\
Type of fast food always taken & 175 & 49.5 \\
Pizza & 78 & 22 \\
Sausage / Hot dog & 67 & 18.9 \\
Hamburger & 5 & 1.4 \\
Fries potato & 18 & 5.1 \\
Fries chicken & 11 & 3.1 \\
None of the above & & \\
Break fast & 244 & 32.4 \\
Yes & 509 & 67.6 \\
No & & \\
Lunch & 476 & 63.2 \\
Yes & 257 & 36.8 \\
No & & \\
Dinner & 322 & 42.8 \\
Yes & 431 & 57.2 \\
No & & \\
\end{tabular}

DISCUSSION: The phenomenal growth that occurs in adolescent's increase energy and nutrient needs [3]. Consuming an insufficient diet during this time can lead to stop or slow growth [4]. On 
the other hand, unsuitable food patterns can also result in diet-related chronic diseases in adulthood $[3,4]$.

The 1994-96 Continuing Survey of Food Intake By Individuals (CSFII) a two day, 24-hour dietary recall data showed that all age groups of children and adolescent girls ages 14-18 years were below recommended guidelines for several nutrients [18].

The analysis of dietary intakes in our study showed that the mean energy intake (1992.4 \pm $753.3 \mathrm{Kcal} / \mathrm{day})$ and the percent of mean energy intake $(66.8 \%$, data not shown), of adolescents were lower than dietary recommended intake.

With regard to growth spurts in adolescents, the actual need of energy in this time varies greatly by physical activity level, basal metabolic rate (BMR), and body composition [16, 17, 18]. The inadequate intake of energy might be related to dieting for weight loss or avoid weight gain, irregular meal patterns $[12,18]$, main meals skipping $[19,20]$, or types of food consumed at breakfast [7].

In our study, more than half $(67.6 \%)$ of the adolescent girls omitted breakfast and dinner $(57.2 \%)$, and nearly one-third of the girls $(36.8 \%)$ avoided lunch. Similar results were reported in Washi et al [3] study.

The low intake of energy, as was observed in the present study, may be associated with high relative prevalence of underweight (16.2\%) compared to overweight (8.6\%), among adolescents in Sistan and Baluchistan Province that was reported in earlier report [13].

The results of the study in relation to the mean E\% of macronutrients among students were within the dietary recommended range for adolescents $[16,17]$. The findings of this study were comparable with values reported by earlier studies [1, 3, 21, 22]. However, a higher E\% of fat was found in some reports $[12,23]$.

The findings on mean protein intake showed an increased consumption in adolescents $(70.1 \pm$ $21.6 \mathrm{~g} /$ day), which was more than the recommended intake (46 gr/day), while the protein $\mathrm{E} \%$ of total calorie intake was within the recommended range for protein intake (10-30\%).

It has been reported that US adolescents consume more than adequate values (almost twice the recommended intake) of protein [18].

In this study more than half $(53.8 \%)$ of the protein consumed obtained from plant sources (low quality proteins) e.g. whole grains and legumes (beans, soya products, split peas, cowpeas, etc). Whereas consumption of the main sources of animal protein with high quality e.g. red meat, fish, poultry (31.9\%), milk and dairy products $(16.3 \%)$ and egg $(3.3 \%)$ were found to be low. It may explain the increase in the daily proportion of protein intake.

The plant proteins contain non-heme iron, so they cannot be considered adequate enough to provide the body's iron needs and protect against the anemia. Also indigestible fibers in many plant sources can inhibit iron and zinc. Adolescents who do not consume animal-derived products are at an increased risk of a low intake of zinc and iron [16].

In the present study $71.5 \%$ and $65.6 \%$ of participations were found to have low iron and zinc intake in comparison with the DRI, respectively. Similar findings were reported in Samuelson et al [24] study.

Besides, $88 \%$ of students were found to consume tea on daily basis and $36.8 \%$ (data not shown) of them drank tea with the meal. 
It has been reported that when tea was drunk with the meal, it significantly inhibited the absorption of non-heam iron (25), and the increase the incidence of anemia in children [26], while an insignificantly adverse effect has been shown on zinc bioavailability after tea consumption [26].

Since tea is a common drink in a number of people, especially in this Province, further research is required to confirm these findings.

Considering that carbohydrates are a main source of dietary energy $[3,18], 87.3 \%$ of subjects in the present study consumed complex carbohydrates (bread, rice or macaroni) daily. The mean daily intake and $\mathrm{E} \%$ of carbohydrate was within the recommended range set by DRI $[16,17]$ on energy intake from carbohydrate (45-65\%). The finding was the same as Bergstrom et al [21] data.

Lifestyle changes during adolescence can result in changes in food habits, as they tend to consume low nutrient density food items like fast foods, sweets and salty foods, skip daily main meals, and have a relatively low vitamin and mineral intake [3,27].

Most adolescents (84.7\%) in the present study were found to eat junk foods (salty snacks: chips/corn chips/popcorn) and almost two fifth (45.5\%) consumed sweet foods. This snack pattern was similar to those of several reports [2,3]. Increased consumption these snacks by children and adolescents leads to a high intake of sugar, salt, and fat, and the inadequate intake of other nutrients such as vitamin A, C, B12, folate, calcium, phosphorus , magnesium and iron[1,3, 22].

Because of accelerated muscular and skeletal growth, and the development of dense bone mass, calcium needs increase during adolescents $[3,16,17]$. In the present study calcium intake was far below the recommended dose, the same as an earlier study [3], but it had no correspondence with Samuelson et al [24] data. The results suggest that high carbonated soft drink consumption (75.4\%) on a daily basis in this population contributes to a low calcium intake by replacing the consumption of milk (16.3\%) on a daily basis.

A carried out by Harnack et al [28], showed that high consumption of soft drinks was found to lessen the consumption of calcium and vitamin $\mathrm{C}$.

The correlation between high a risk of bone fractures and the increased consumption of soft drinks was reported in a study by Bigler-Doughten et al [29].

The findings showed that almost $61.9 \%$ of students had an intake lower of vitamin $\mathrm{C}$ than the recommended values. This is in parallel to the inadequate consumption of fruit, vegetables and fresh juices, which only $16.2 \%, 2.7 \%$ of students were found to consume them daily, and $62 \%$ seldom ate fruits and vegetables. This finding is dealing with those of several reports [3, 23] study, but it had no correspondence with McNaughton et al [2] data.

Also these foods are considerable sources of vitamins such as folate. This vitamin plays an important role in DNA, RNA, and protein synthesis.

Adequate intake of folate is important for girls who may become pregnant [16]. In our study, $97.2 \%$ of adolescents had been shown to have a folate deficiency. It has been reported that adolescents spend a more time outside the home with their friends. One third of them eat readyto-eat foods away from home [3]. High consumption of fast foods has been associated with high in added fat, sweeteners, and sodium [3, 17].

On the other hand, fast foods are often accompanied by soft drinks [3], as shown in this study; $47 \%$ of the adolescents consumed different fast foods along with soft drink. Nearly half 
(49.5\%) tended to consume pizza and two fifth (40.9\%) consumed Sausages/Hot dogs and Hamburgers.

The mean E\% of total fat among Sistan and Baluchistan Province adolescents was within the recommended range for fat intake (20-35\%) of total energy intake.

One possible reason might be explained by their less frequent consumption of fat-rich foods such as meats, eggs, milk, and dairy products.

CONCLUSIONS: Nutrient data collected for two days, a 24-hour dietary recall and food frequency suggests that a low intake of milk and dairy products "a good source of protein and calcium", fruits and vegetables, and high consumption of empty calorie foods e.g. sweets, salty snacks, soft drinks and junk foods by adolescents of Sistan and Baluchistan could lead to an increased risk of a micronutrients deficiency and diet-related diseases in later life. Thus, considering to social, economic, and cultural conditions in this area, it seems an implementation of interventional programs towards healthier food patterns can help young people improve dietary nutritional quality, and avoid unbalanced diets for delaying or preventing the development of chronic diseases.

LIST OF ABBREVIATIONS: Food frequency questionnaire (FFQ); Dietary Reference Intake (DRI); Energy percent (E \%); Continuing Survey of Food Intake By Individuals (CSFII); Basal metabolic rate (BMR).

Acknowledgement and Funding: This work was financially supported by the Organization of Education, Zahedan Sistan and Bluchistan Province, Iran. The authors would like to thank all students, parents, and teachers of the high schools of Sistan and Baluchistan Province who participated in this study and the persons who performed the data collection.

Conflict of interest: None declared

\section{REFERENCES:}

1. Gharib N, Rasheed P.Energy and macronutrient intake and dietary pattern among school children in Bahrain: a cross-sectional study. Nutr J 2011, 10:62.

2. McNaughton SA, Ball K, Mishra GD, Crawford DA. Dietary Patterns of Adolescents and Risk of Obesity and Hypertension. J Nutr. 2008, 138(2):364-70.

3. Washi SA, Ageib MB. Poor diet quality and food habits are related to impaired nutritional status in 13 - to 18- year-old adolescents in Jeddah. Nutr Res. 2010, 30(8):527-34.

4. Woodruff B A, Duffield A. Anthropometric assessment of nutritional status in adolescent populations in humanitarian emergencies Eur J Clin Nutr 2002, 56 (11): 1108- $\square 1118$.

5. Li S, Chen W, Srinivasan SR, Tang R, Bond MG, Berenson GS. Race (black-white) and gender divergences in the relationship of childhood cardiovascular risk factors to carotid artery intima-media thickness in adulthood: the Bogalusa Heart Study. Atherosclerosis 2007, 194:421-425.

6. Raitakari OT, Juonala M, Viikari JS.Obesity in childhood and vascular changes in adulthood: insights into the Cardiovascular Risk in Young Finns Study. Int J Obes (Lond). 2005, 29 Suppl 2:S101-4. 
7. Mihas C, Mariolis A, Manios Y, Naska A, Arapaki A, Mariolis-Sapsakos T, Tountas Y. Evaluation of a nutrition intervention in adolescents of an urban area in Greece: short- and long-term effects of the VYRONAS study. Public Health Nutr 2009, 13(5): 712-719.

8. ACC/SCN. Fourth Report on the world nutrition situation - Nutrition throughout the life cycle, Geneva: ACC/SCN in collaboration with IFPRI, 2000, (http:// www.unsystem.org/scn/ Publications/ 4RWNS/4rwns.pdf, accessed 26 May 2005).

9. Aounallah-Skhiri H, Traissac P, El Ati J, Eymard-Duvernay S, Landais E, Achour N, Delpeuch F, Ben Romdhane H , Maire B . Nutrition transition among adolescents of a southMediterranean country: dietary patterns, association with socio-economic factors, overweight and blood pressure. A cross-sectional study in Tunisia. Nutr J. 2011, 10: 38.

10. Grarrow JS, James WPT, Ralph, A. Infancy, childhood and adolescent. Human Nutrition and Dietetics, $10^{\text {th }}$ edn. Churchill Livingstone: Edinburgh 2000, 460-461.

11. Yannakoulia M, Karayiannis D, Terzidou M, Kokkevi A, Sidossis LS. Nutrition-related habits of Greek adolescents. Eur J Clin Nutr. 2004, 58(4):580-6.

12. Boschi V, Siervo M, D’Orsi P, Margiotta N, Trapanese E, Basile F, Nasti G, Papa A, Bellini O, Falconi C. Body Composition, Eating Behavior,Food-Body Concerns and Eating Disorders in Adolescent Girls. Ann Nutr Metab 2003, 47: 284-293.

13. Montazerifar F, Karajibani M, Rakhshani F, Hashemi H. Prevalence of underweight,overweight and obesity among highschool girls in Sistan va Baluchistan. East Mediterr Health J 2009, 15(5):993-1000.

14. Molag ML, de Vries JHM, Duif N, Ocke MC, Dagnelie PC. Goldbohm RA, van 't Veer P. Goldbohm RA, van 't Vee $r$ P. Selecting informative food items for compiling food-frequency questionnaires: comparison of procedures. Br J Nutr 1995,73(4): 531-50.

15. Frank GC, Nicklas TA, Webber LS, Major C, Miller JF, Berenson GS.A food frequency questionnaire for adolescents: defining eating patterns. J Am Diet Assoc. 1992, 92(3):313-8.

16. Institute of Medicine, Food and Nutrition Board, Standing Committee on the Scientific Evaluation of Dietary Reference Intakes, Subcommittees on Upper Reference Levels of Nutrients and Interpretation and Uses of Dietary References Intakes, Panel on Micronutrients. Dietary reference intakes for energy, protein and amino acids, carbohydrate, fiber, fat, fatty acids, cholesterol (macronutrients). Washington, DC: National Academy Press, 2002 (prepress). Available to read at: URL: http://www.nap.edu.

17. Mahan LK,Escott-stump S. Krause's food nutrition \& diet therapy $.12^{\text {th }}$ ed. St Louis: WB saunders company 2008, 246-266, 339, 341.

18. Gleason P, Suitor C. Children's diets in the mid-1990s: dietary intake and its relationship with school meal participation. Special nutrition programs; report no. CN-01-CD1. Alexandria, VA: US Department of Agriculture, Food and Nutrition Service; 2001. Accessed 8/17/04. http://www.fns.usda.gov/oane/MENU/Published/CNP/cnp.htm.

19. Lieke GM, Raaijmakers, Kathelijne M. H. H. Bessems, Stef P. J. Kremers,Patricia van Assema. Breakfast consumption among children and adolescents in the Netherlands. Eur J Public Health 2009 , 20( 3): 318-324.

20. Shaw ME. Adolescent breakfast skipping: an Australian study. Adolescence 1998; 33:851-61.

21. Bergström E, Hernell O, Persson LA.Dietary changes in Swedish adolescents. Acta Paediatr. 1993 ,82(5):472-80. 
22. Matthys C, De Henauw S, Devos C, De Backer G. Estimated energy intake, macronutrient intake and meal pattern of Flemish adolescents. Eur J Clin Nutr 2003; 57: 366-375.

23. Paulus D, Saint-Remy A, Jeanjean M. Dietary habits during adolescence: results of the Belgian Adolux Study. Eur J Clin Nutr 2001, 55 (2): 130-136.

24. Samuelson G .Dietary habits and nutritional status in adolescents over Europe. An overview of current studies in the Nordic countries. Eur J Clin Nutr. 2000, 54 (Suppl 1):21-8.

25. Disler PB, Lynch SR, Charlton RW, Torrance JD, Bothwell TH, Walker RB, Mayet F .Effect of tea on iron absorption. Gut 1975, 16: 193-200.

26. Ganji V, Kies CV. Zinc bioavailability and tea consumption. Studies in healthy humans consuming self-selected and laboratory-controlled diets. Plant Food Hum Nutr 1994 , 46 267276.

27. Aounallah-Skhiri H, Romdhane HB, Traissac P, Eymard-Duvernay S, Delpeuch F, Achour N, Maire B. Nutritional status of Tunisian adolescents: associated gender, environmental and socio-economic factors. Public Health Nutr. 2008, 11(12):1306-17.

28. Harnack L, Stang J, Story M. Soft drink consumption among US children and adolescents: nutritional consequences. J Am Diet Assoc. 1999 , 99(4):436-41.

29. Bigler-Doughten S, Jenkins RM. Adolescent snacks, nutrient density and nutritional contribution to total intake. J Am Diet Assoc 1987, 87(12):1678-9. 